\title{
Development of the models to estimate particulate matter from thermal infrared band of Landsat Enhanced Thematic Mapper
}

\author{
J. Amanollahi • C. Tzanis • A. M. Abdullah • \\ M. F. Ramli • S. Pirasteh
}

Received: 16 December 2011/Revised: 25 September 2012/Accepted: 9 December 2012/Published online: 9 January 2013

(c) CEERS, IAU 2013

\begin{abstract}
Particulate matter concentration and assessment of its movement pattern is crucial in air pollution studies. However, no study has been conducted to determine the $\mathrm{PM}_{10}$ concentration using atmospheric correction of thermal band by temperature of nearest dark pixels group (TNDPG) of this band. For that purpose, 16 Landsat Enhanced Thematic Mapper plus ETM+ images for Sanandaj and Tehran in Iran were utilized to determine the amount of $\mathrm{PM}_{10}$ concentration in the air. Thermal infrared (band 6) of all images was also used to determine the ground station temperature (GST b6) and temperature of nearest dark pixels group. Based on atmospheric correction of images using temperature retrieval from Landsat ETM+, three empirical models were established. Nonlinear correlation coefficient with polynomial equation was used to analyze the correlations between particulate matter concentration and the ground station temperature for the three models. Similar analyses were also undertaken for three stations in Klang Valley, Malaysia, using 11 Landsat ETM+ images to show the effectiveness of the model in different region. The data analysis indicated a good correlation coefficient $R=0.89$ and $R=0.91$ between the
\end{abstract}

J. Amanollahi ( $₫)$ · A. M. Abdullah · M. F. Ramli Department of Environment Sciences, Faculty of Environmental Studies, Universiti Putra Malaysia, Serdang 43400, Malaysia e-mail: rs.environment@gmail.com

C. Tzanis

Faculty of Physics, Division of Environmental Physics and Meteorology, UoAthens Climate Research Group,

University of Athens, Athens, Greece

S. Pirasteh

Department of Geography and Environmental Management, Faculty of Environment, University of Waterloo,

Waterloo, Canada trend of the result of temperature of nearest dark pixels group b6 - (GST b6 - GST) model and the trend of $\mathrm{PM}_{10}$ concentration in Iran and Malaysia, respectively. This study reveals the applicability of the thermal band of Landsat TM and ETM+ to determine the $\mathrm{PM}_{10}$ concentration over large areas.

Keywords Digital number - Dark pixel - Land surface temperature - Atmospheric correction - Wind speed

\section{Introduction}

Suspended particulate matters (SPM) in the atmosphere with solid and liquid physical states are produced by natural and anthropogenic sources. Sea salt from the oceans, volcanic eruptions, and windblown dust are from the natural sources. Anthropogenic sources consist of heat and power generation, motor vehicle exhaust, industrial processes, and open burning activities (Kaufman et al. 2002). However, the atmosphere transformation processes such as $\mathrm{NO}_{\mathrm{X}}$ to nitrates (Wang et al. 2006) and $\mathrm{SO}_{2}$ to sulfates (Quan et al. 2008) at urban and industrial areas may also cause SPM. The study of particulate matter (PM) is important because of its effects on human health (Adamson et al. 1999; Williams et al. 2003; WHO 2005), atmospheric visibility (Seinfeld and Pandis 1998), climate change (Haywood and Boucher 2000), satellite imagery (Hadjimitsis et al. 2004; Hadjimitsis and Clayton 2008), as well as the nutrient balance and acidity of soil (Yun et al. 2002; Odabasi and Bagiroz 2002). The PM with sizes of less than 10 and $2.5 \quad \mathrm{M}_{10}$ and $\mathrm{PM}_{2.5}$, respectively (Krewski et al. 2000). The study of PM concentration and other atmospheric pollutants usually relies on spatial and temporal data series measured in ground station sites in cities 
and rural areas (Al-Saadi et al. 2005). Ground site measurements entail high installation and maintenance costs. Furthermore, the data collected through these methods are reliable only within the spatial coverage of only a few meters around the station. High variability of air quality and scarce distribution of ground station sites impede mapping atmospheric pollution using ground monitor stations (Wald et al. 1999). The major benefit of air quality monitoring by satellite sensors is that it yields accurate observation of data from small and large areas (Hadjimitsis et al. 2002). In the last decade, spectral and angular or polarization properties of solar radiation by aerosol were utilised to design several satellite sensors to measure global aerosol concentration. Earth observation system-moderate resolution imaging spectrograph (EOS-MODIS) uses spectral properties (King et al. 1992), EOS-multi angle imaging spectroradiometer (MISR) uses angular characteristics (Martonchik and Diner 1992), while advance earth observing system ocean-polarization and directionality of earth's reflectance (ADEOS-POLDER) uses polarization measurements to measure aerosol concentration. The method for MODIS aerosol optical thickness (AOT) retrieval is based on dark surface targets in the blue and red channel and uses the $2.2 \mu \mathrm{m}$ channel for their detection (Kaufman et al. 1997). In this method, it has been assumed that the aerosol effect is negligible at $2.2 \mu \mathrm{m}$ versus that at the blue and red channels. Previous studies on the relationship between MODIS AOT and PM in troposphere measured by ground stations (Chrysoulakis et al. 2003; Wang and Christopher 2003; Sohrabinia and Khorshiddoust 2007; Kampe 2008), and MISR product and PM (Mazzoni et al. 2007) have been undertaken. Some of the limitations of using MODIS data include the big size of the MODIS pixel aerosol product (level 2 AOT product has a $10 \mathrm{~km}$ resolution), variation of correlation coefficients between MODIS product and PM concentration depending on the location (Chrysoulakis et al. 2003), as well as weak correlation coefficients between MODIS product and PM concentration in some studies, e.g., $R=0.56$ for Beijing (Ling-jun et al. 2007), $R=0.48$ for Sydney (Gupta et al. 2007), $R=0.46$ for Sanandaj, Iran (Amanollahi et al. 2011b), and $R=0.33$ for Kuala Lumpur (Amanollahi et al. 2011a). These results have led researchers to look for a more suitable satellite. Landsat Thematic Mapper (TM) band 1 with $30 \mathrm{~m}$ resolution was utilized to assess the air pollution in Athens by testing the correlation of the AOT and air pollutants (Retalis 1998; Retalis et al. 1999). Hadjimitsis and Clayton (2009) determined the AOI via atmospheric correction for Landsat TM bands 1 and 2. This method was based on water vapor absorption that is negligible in Landsat TM as bands 1 and 2 (Kaufman 1989). In the last decade, some studies were undertaken to calibrate long wavelength (thermal infrared) of Landsat TM and
Enhanced Thematic Mapper Plus (ETM+) which are used to determine the land surface temperature (Schott et al. 2001; Barsi et al. 2007). Schott et al. (2001) as well as Barsi et al. (2007) showed a $3 \mathrm{~K}$ temperature differences in the onboard calibration of Landsat ETM+. Barsi et al. 2007 calibrated the TM thermal band and found $0.7 \mathrm{~K}$ at $300 \mathrm{~K}$ temperature differences. The assumption of this study is that the calibration of the thermal infrared band of Landsat ETM depends on the amount of PM in the air. Thus, the objective of this study is to assess $\mathrm{PM}_{10}$ concentration in Iran and Malaysia using the calibration of thermal infrared band of the Landsat ETM+.

\section{Materials and methods}

Study area

The study areas are located in Tehran and Sanandaj in Iran, and Petaling Jaya, Shah Alam, and Cheras, Malaysia.

\section{Iran}

Tehran is Iran's largest urban area and city (Fig. 1d) and as the capital of Tehran province, it faces many serious air pollution problems. Every year, air pollution in Tehran is associated with deaths of many citizens (MHME 2010). In November, December, and January every year, the inversion phenomena over the city of Tehran increased air pollution density and in most cases air pollution reached alarming levels (MHME 2010). Consequently, the government declared public holiday in Tehran and citizens are advised to stay at home with doors closed (MHME 2010). Air pollution had incurred financial losses around $\$ 3.3$ billion in the current Iranian calendar year. Sanandaj, the capital of Kurdistan province (Fig. 1c), is located in the west of Iran (Fig. 1a). In the last few years, Sanandaj has received dust storms from Iraq. Amanollahi et al. (2010b) showed that wind erosion in desert of Northern Saudi Arabia, Western Iraq, and Eastern Syria were responsible for dust storms in this area. The severe dust storms that occurred from 4 to 10 July 2009 increased the average values of $\mathrm{PM}_{10}$ in Sanandaj from 107 to $2,976 \mu \mathrm{g} \mathrm{m}^{-3}$ on 3 and 5 July 2009, respectively (IDOE 2009). The maximum $\mathrm{PM}_{10}$ concentration during this dust storm was $5,616 \mu \mathrm{g} \mathrm{m}^{-3}$ at 2 a.m. on 5 July 2009.

\section{Malaysia}

Petaling Jaya, Shah Alam, and Cheras are located in Klang Valley, Malaysia. Klang Valley is a part of Selangor, and is located in the central part of the west coast of Peninsular Malaysia (Fig. 1b). Klang Valley covers an area of about 


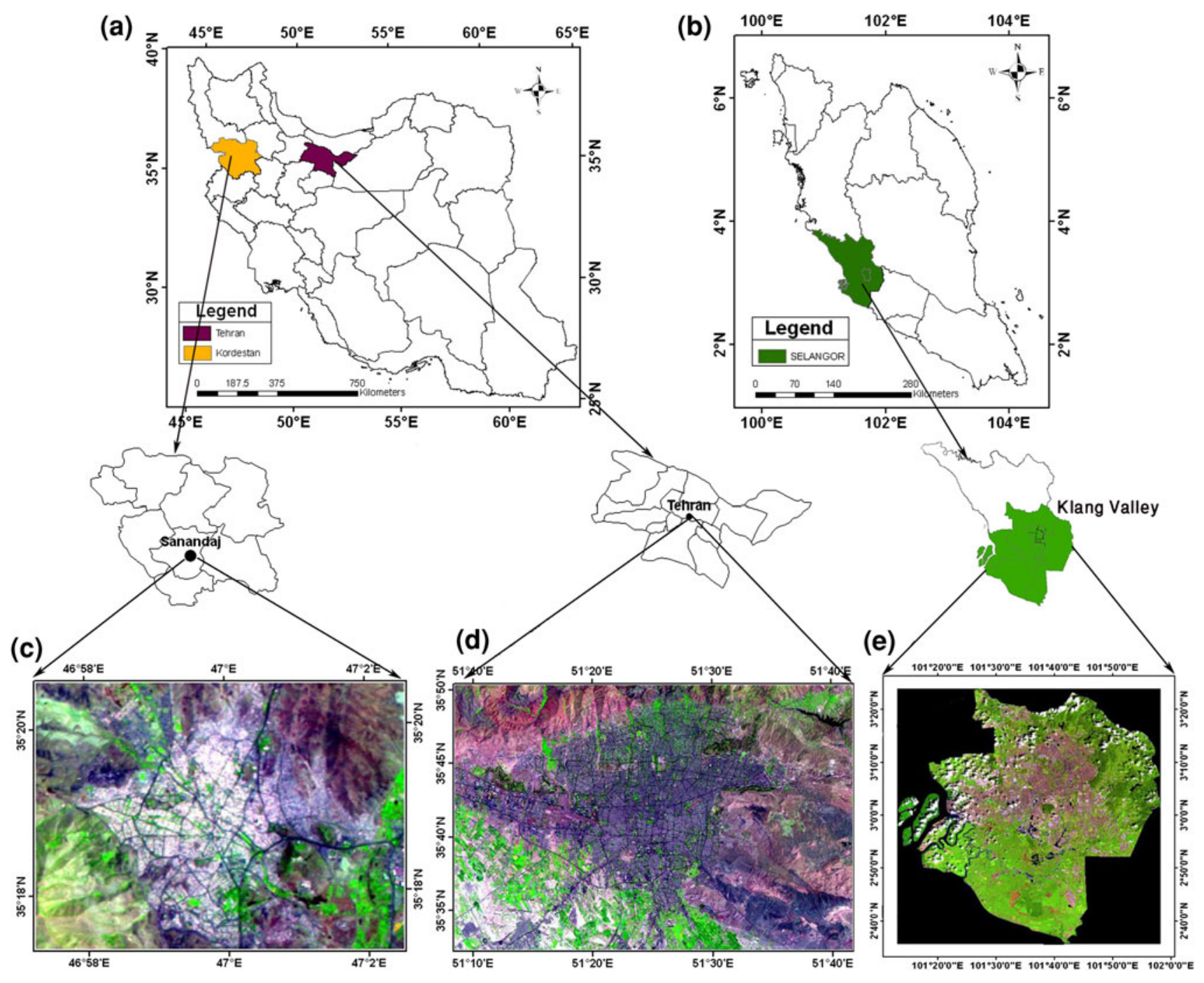

Fig. 1 Color areas in a and $\mathbf{b}$ shows the study area in Iran, and Malaysia respectively. $\mathbf{c}$ and $\mathbf{d}$ shows the Sanandaj and Tehran cities in 8 July and 1 Jun 2009, respectively. e shows the Klang valley area in 15 December 2006

$2,826 \mathrm{~km}^{2}$ and it is geographically delineated by Strait of Malacca to the west and the Titiwangsa Mountains to the north and east, this region is located in a bowl-like topography. Malaysian climate is classified into the rainy season from October to January, and dry season from February to September regarding the amount of humidity, temperature, and rainfall (MMD 2009). Air pollution in Klang Valley is higher than other areas in Malaysia due to its geographical position, large-scale industrial and commercial activities, densely populated areas, and high vehicular traffic (EQR 2006).

Data and image

The data utilised in this study are ground stations data of $\mathrm{PM}_{10}$ concentrations and ground station temperature (GST); and the data retrieved from thermal band (band 6) of Landsat ETM+ images (GST b6) (Table 1) and temperature of nearest dark pixels group (TNDPG b6) retrieved from thermal band (band 6) of Landsat ETM+ images (Table 1). The $\mathrm{PM}_{10}$ data for Tehran were acquired from Urban Air Quality Assessment and Management (TM 2010), and for Sanandaj were obtained from Iranian Department of Environment (IDOE 2010). The GST data were provided from Iran Metrological Organization for both areas (IMO 2010). $\mathrm{PM}_{10}$ and GST data for Klang Valley were received From Malaysian Department of Environment (MDOE 2010). The GST data which were acquired coincided with the Landsat satellite acquisition over the study areas. In order to obtain GST b6, the thermal band (band 6) of 8, 8, and 11 ETM+ images were used for Tehran, Sanadaj, and Klang Valley area, respectively (Table 1). 
Table 1 The date of Landsat ETM+ images of Klang Valley, Tehran and Sanandaj that were utilized in this study

\begin{tabular}{|c|c|c|c|c|c|c|c|c|c|}
\hline \multirow[t]{2}{*}{ Landsat image } & \multicolumn{3}{|c|}{ Klang Valley } & \multicolumn{3}{|c|}{ Sanandaj } & \multicolumn{3}{|c|}{ Tehran } \\
\hline & Date & Month & Years & Date & Month & Years & Date & Month & Years \\
\hline \multirow[t]{11}{*}{ ETM+ } & 15 & November & 2004 & 14 & June & 2009 & 9 & June & 2009 \\
\hline & 1 & December & 2004 & 17 & August & 2009 & 27 & July & 2009 \\
\hline & 17 & December & 2004 & 2 & September & 2009 & 12 & August & 2009 \\
\hline & 7 & March & 2005 & 14 & October & 2009 & 13 & September & 2009 \\
\hline & 9 & February & 2007 & 3 & July & 2010 & 15 & October & 2009 \\
\hline & 13 & March & 2007 & 4 & August & 2010 & 16 & November & 2009 \\
\hline & 14 & April & 2007 & 5 & September & 2010 & 25 & April & 2010 \\
\hline & 5 & September & 2007 & 7 & October & 2010 & 11 & May & 2010 \\
\hline & 19 & June & 2008 & & & & & & \\
\hline & 6 & April & 2010 & & & & & & \\
\hline & 12 & August & 2010 & & & & & & \\
\hline
\end{tabular}

Band 4 of all images was utilized for qualification of monitoring ground stations by linking the bands. Bands 5 , 4 , and 3 were used to show the true or false color (Fig. 1c, d, e). Bands 6, 5, 4, and 3 of all images were rectified to UTM projection system (datum WGS84, zone $38^{\circ} \mathrm{N}, 39^{\circ} \mathrm{N}$ ) for Iran and (datum WGS84, zone $47^{\circ} \mathrm{N}$ ) for Malaysia and were georeferenced using nearest neighbor resampling algorithm ( $\mathrm{Li}$ et al. 2009) based on a topographical map $(1: 25,000)$ from National Cartographic Center of Iran and Malaysia using 50 ground control points. The RMSEs for each band rectification were lower than 1 pixel.

\section{Retrieval of GST b6 from Landsat ETM+}

The DNs of pixel were converted to spectral radiance according to the sensor hand book (Landsat 7 Science Data User Hand Book 2010):

$\left.L_{\lambda}=\left(\left(L_{\max }-L_{\min }\right) /\left(Q C a l_{\max }-Q C a l_{\min }\right)\right) \times Q C a l\right)+L_{\min }$

where $L_{\lambda}=$ spectral radiance, $Q C a l_{\max }=255, Q C a l_{\min }=$ 1, $Q C a l=\mathrm{DN}, L_{\max }, L_{\min }=$ spectral radiance for band 6 at DN 255 and 1 , respectively $\left(\mathrm{W} / \mathrm{m}^{2}\right.$ ster $\left.\mu \mathrm{m}\right)$. As a second step, Eq. (4) was used to convert the spectral radiance of pixel to black body temperature:

$T=K_{2} / \operatorname{Ln}\left(K_{1} / L_{\lambda}\right)+1$

where $T$ is the effective at satellite brightness temperature in Kelvin; $K_{1}=$ first calibration constant $\left(\mathrm{W} / \mathrm{m}^{2}\right.$ ster $\left.\mu \mathrm{m}\right)$ $=666.09, K_{2}=$ second calibration constant in Kelvin $=1,282.7$, and $L_{\lambda}=$ spectral radiance $\left(\mathrm{W} / \mathrm{m}^{2}\right.$ ster $\left.\mu \mathrm{m}\right)$.

The GSTs b6 of ETM+ images were subtracted from 273.15 for converting the Kelvin to Centigrade ( $\mathrm{Xu}$ and Chen 2004).

\section{Results and discussion}

Relationship between wind speed and GST, GST b6, and $\mathrm{PM}_{10}$

The assumption of the method is that the thermal value recorded at any pixel does not represent the true ground radiant temperature where part of the temperature is contributed by the atmospheric pollution (scattering and absorption) especially SPM. The wind speed may also affect the $\mathrm{PM}_{10}$ concentration (Jonsson et al. 2004) and GST (Agarwal and Tandon 2010) which consequently may affect GST b6 retrieval from images. In order to gain a better understanding of the atmospheric condition during the time when the images were taken, the relationship between wind speed with GST, $\mathrm{PM}_{10}$ concentration and GST b6 retrieval from images were analyzed using nonlinear correlation coefficient (NLCC) (Table 2).

The higher standard deviation (SD) in GST and GST b6 for Tehran compared to Sanandaj and Klang Valley was probably due to the seasonal differences. The minimum SD was obtained during winter (January) and the maximum was in summer (August) (Table 1). The SD also may be affected by the thickness of vegetation cover which is low in winter and high in summer (Amanollahi et al. 2010a). In contrast, in Sanandaj, the maximum and minimum amounts of GST and GST b6 were obtained in summer (August) and autumn (October) which were low. The high SD in $\mathrm{PM}_{10}$ concentration over Sanandaj could be attributed to the dust storms from Iraq especially during summer (Amanollahi et al. 2011b). This situation increased the $\mathrm{PM}_{10}$ concentrations within a short period. In tropical Klang Valley, temperature is always between 20 and $36{ }^{\circ} \mathrm{C}$ along the year which is similar to summer temperature. Thus, SD in GST 
Table 2 Correlation statistics between wind speed with GST b6, GST, and $\mathrm{PM}_{10}$ concentration in, Petaling Jaya, Shah Alam, and Cheras in Malaysia as well as Sanandaj and Tehran in Iran

\begin{tabular}{|c|c|c|c|c|c|c|c|c|c|}
\hline \multirow[t]{2}{*}{ Stations } & \multicolumn{3}{|c|}{ Wind speed } & \multicolumn{2}{|c|}{ GST $\left({ }^{\circ} \mathrm{C}\right)$} & \multicolumn{2}{|c|}{$\mathrm{PM}_{10}\left(\mu \mathrm{g} \mathrm{m}^{-3}\right)$} & \multicolumn{2}{|c|}{ GST b6 $\left({ }^{\circ} \mathrm{C}\right)$} \\
\hline & Min & $\operatorname{Max}$ & SD & SD & C.C (R) & SD & C.C (R) & SD & C.C (R) \\
\hline Tehran & 0 & 12 & 3.24 & 9.2 & 0.36 & 29 & 0.15 & 11.8 & 0.21 \\
\hline Sanandaj & 0 & 5 & 1.33 & 5.0 & 0.28 & 120 & 0.16 & 3.8 & 0.29 \\
\hline Petaling Jaya & 3.4 & 9 & 1.7 & 0.69 & 0.10 & 13.8 & 0.11 & 2.5 & 0.25 \\
\hline Shah Alam & 4.9 & 14.5 & 3.4 & 1.40 & 0.14 & 19.2 & 0.33 & 3.5 & 0.35 \\
\hline Cheras & 3.8 & 9.6 & 1.6 & 0.58 & 0.12 & 10.6 & 0.14 & 2.8 & 0.15 \\
\hline
\end{tabular}

and GST b6 was low. The correlation coefficients between wind speed with GST, $\mathrm{PM}_{10}$ concentration, and GST b6 retrieved from images for all areas were low (Table 2) and positive. These results are in contrast with the finding of Jonsson et al. (2004) and Agarwal and Tandon (2010) which is probably due to the low wind speed and stable atmospheric condition during the image acquisition for all the study areas. On the other hand, the mesoscale wind produced by urban heat island increased the air pollution by circulated the pollutants in upward direction (Agarwal and Tandon 2010). This result emphasizes the fact that any difference between GST b6 retrieval from images and GST is due to an interaction of earth surface radiation with atmospheric pollution, especially the PM.

\section{Models development}

The aim of atmospheric correction is to compensate the atmospheric effect to the image (Hadjimitsis and Clayton 2009). Previous researchers used different ground targets for removing atmospheric effects on band 6 such as lake (Schott et al. 2001; Barsi et al. 2007) and rice crop (Coll et al. 2010) due to their high homogeneity. Schott et al. (2001) used water to increase the validation result of thermal calibration of Landsat ETM+. The qualities of water as a good thermal calibration are (1) thermal stability, (2) covering at least a few pixels, (3) a well-known emissivity, and (4) homogeneity (Schott et al. 2001). Three models were established to predict the $\mathrm{PM}_{10}$ concentration in the atmosphere based on atmospheric correction method of b6 of the study areas (Table 3). Pool in Eram Park for Tehran, Vhadat Lake for Sanandaj, and the retention ponds around the three stations in Klang Valley were used to determine the TNDPG b6 in the images. In order to make any model, the details of the parameters used in the model should be known. Thus, GST b6 is the function of three factors as follows:

$\mathrm{GST} \mathrm{b} 6=\mathrm{GST}+\mathrm{AEEGS}+\mathrm{ES}$

where GST is the ground station temperature, AEEGS is the atmospheric effect on emission of ground station, and ES is the emissivity of station.
TNDPG b6 is the second parameter used in the models and is a function of three factors as follows:

TNDPG $\mathrm{b} 6=\mathrm{DPT}+\mathrm{AEEDP}+\mathrm{ED}$

where DPT is the dark pixel temperature, AEEDP is the atmospheric effect on emission of dark pixel, and ED is the emissivity of dark pixel which is 0.985 (Schott et al. 2001).

In order to determine the relationship between trends of satellite temperature and $\mathrm{PM}_{10}$ concentration, three simple models were empirically established based on GST b6, GST, and TNDPG b6 (Eq. 5). The aim of the Eq. (5) is to clarify the atmospheric effect of both emissions including water and ground stations in the result. However, the ES and DPT are also other parts of the result.

GST b6 + TNDPG b6 - GST $=$ PMP

$\mathrm{AEEGS}+\mathrm{GST}+\mathrm{ES}+\mathrm{DPT}+\mathrm{AEEDP}+\mathrm{ED}-\mathrm{GST}=\mathrm{PMP}$

$\mathrm{AEEGS}+\mathrm{AEEDP}+0.985+\mathrm{ES}+\mathrm{DPT}=\mathrm{PMP}$

where PMP is PM predication. Eq. (6) is based on the simple assumption that any differences between GST b6 and GST may be due to the atmospheric effects on emission of the ground stations and also shows the AEEGS and ES effects on the results.

GST b6 - GST $=$ PMP

$\mathrm{AEEGS}+\mathrm{GST}+\mathrm{ES}-\mathrm{GST}=\mathrm{PMP}$

$\mathrm{AEEGS}+\mathrm{ES}=\mathrm{PMP}$

The aim of Eq. (7) is to eliminate the ES which depends on the temperature, emission angle, and wavelength. For that purpose, the AEEDP and DPT of TNDPG b6 are subtracted from AEEGS and ES of GST b6.

TNDPG b6 $-($ GST b6 - GST $)=$ PMP

$\mathrm{DPT}+\mathrm{AEEDP}+\mathrm{ED}-(\mathrm{AEEGS}+\mathrm{GST}+\mathrm{ES}-\mathrm{GST})=\mathrm{PMP}$

$\mathrm{DPT}+\mathrm{AEEDP}+0.985-\mathrm{AEEGS}-\mathrm{ES}=\mathrm{PMP}$

For a closer consideration of the trend of $\mathrm{PM}_{10}$, the $\mathrm{PM}_{10}$ data were divided into three groups of $0-50,50-100$, and $100 \mu \mathrm{g} \mathrm{m}^{-3}<\mathrm{PM}$. The results from the proposed method were undertaken for all the data collected in different areas in Iran and Malaysia separately. The trend 
Table 3 NLCC between different empirical models of temperature retrieval from Landsat ETM+ and $\mathrm{PM}_{10}$ concentrations over Sanandaj, Tehran and Klang Valley

Fig. 2 NLCC between different empirical models of temperature retrieval from Landsat ETM+ and $\mathrm{PM}_{10}$ concentrations in $50-100$ $\left(\mu \mathrm{g} \mathrm{m}^{-3}\right)$ in Tehran Iran
Fig. 3 NLCC between different empirical models of temperature retrieval from Landsat ETM+ and $\mathrm{PM}_{10}$ concentrations in $50-100\left(\mu \mathrm{g} \mathrm{m}^{-3}\right)$ in Sanandaj, Iran

\begin{tabular}{|c|c|c|c|c|}
\hline \multirow[t]{2}{*}{ Models } & \multicolumn{3}{|c|}{$\mathrm{PM}_{10}\left(\mu \mathrm{g} \mathrm{m}^{-3}\right)$ in Iran } & \multirow{2}{*}{$\begin{array}{l}\mathrm{PM}_{10}\left(\mu \mathrm{g} \mathrm{m}^{-3}\right) \text { in Malaysia } \\
0-50\end{array}$} \\
\hline & $0-50$ & $50-100$ & $100<\mathrm{PM}_{10}$ & \\
\hline$(\mathrm{GST}$ b6 + TNDPG b6 - GST) & 0.42 & 0.17 & 0.55 & 0.13 \\
\hline$(\mathrm{GST}$ b6 - GST) & 0.60 & 0.39 & 0.63 & 0.17 \\
\hline TNDPG b6 - (GST b6 - GST) & 0.61 & 0.82 & 0.67 & 0.52 \\
\hline
\end{tabular}
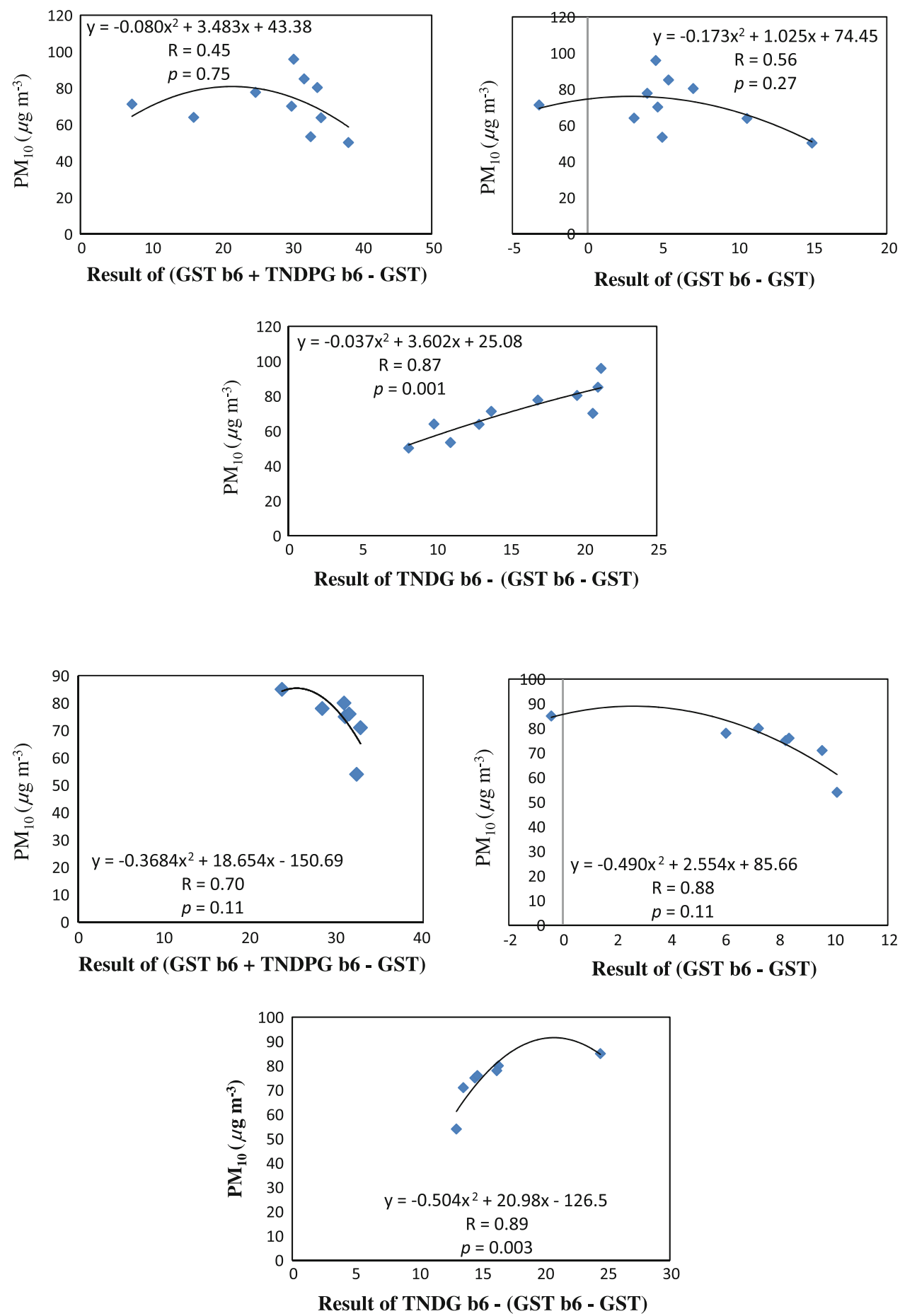

empirical models of temperature retrieval from Landsat ETM+ and $\mathrm{PM}_{10}$ concentrations in $0-50\left(\mu \mathrm{g} \mathrm{m}^{-3}\right)$ in Petaling Jaya, Malaysia
Fig. 4 NLCC between different
Fig. 5 NLCC between different empirical models of temperature retrieval from Landsat ETM+ and $\mathrm{PM}_{10}$ concentrations in $0-50\left(\mu \mathrm{g} \mathrm{m}^{-3}\right)$ in Shah Alam, Malaysia
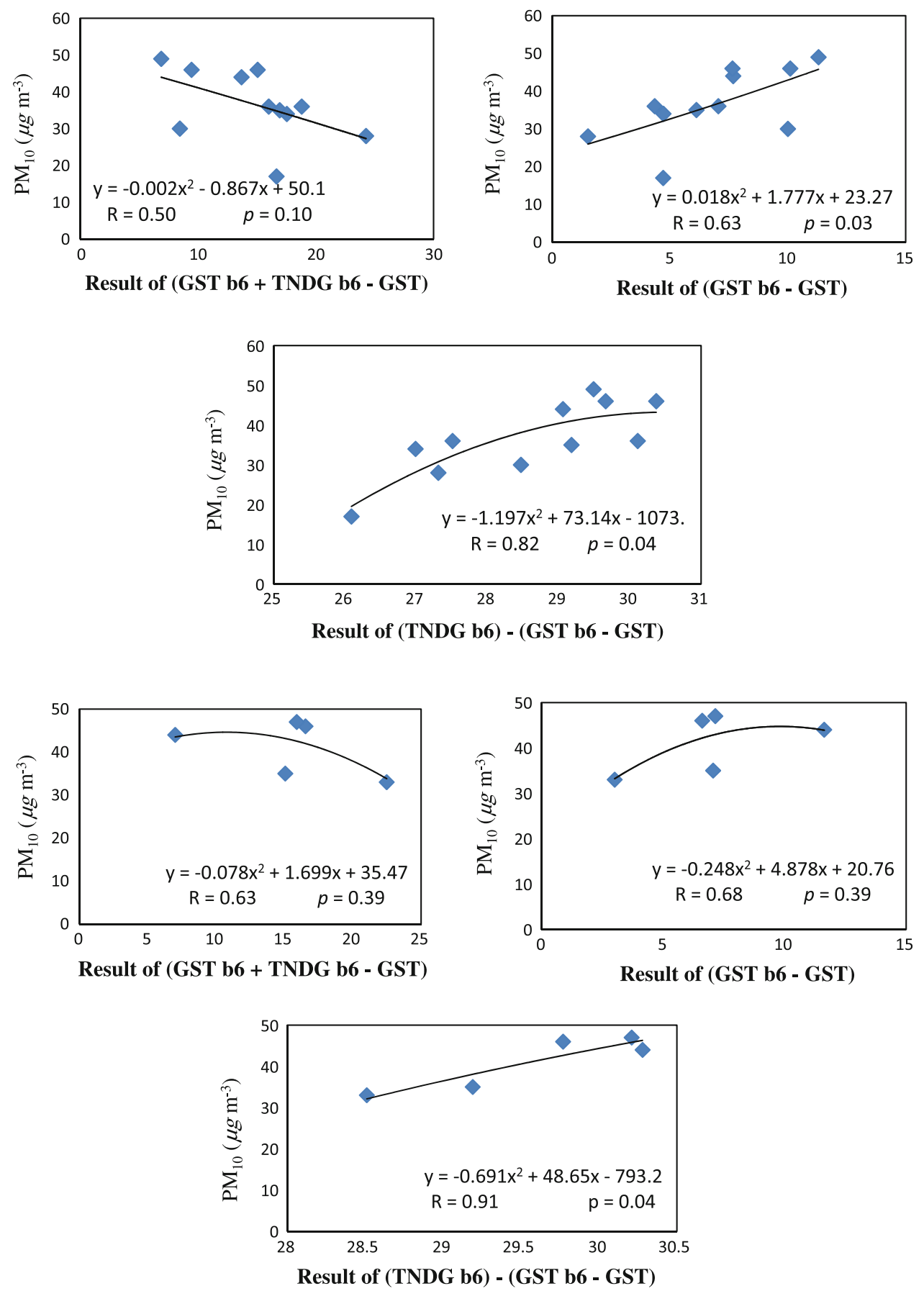

of NLCC for different amounts of $\mathrm{PM}_{10}$ concentration depends on different models of GST retrieval shown in Table 3 for all the study areas. The lowest and highest NLCC values in the total result were obtained when (GST b6 + TNDPG b6 - GST) model with PM $_{10}$ with 0-50 $\mu \mathrm{g} \mathrm{m}^{-3}$ and TNDPG b6 - (GST b6 - GST) model with $\mathrm{PM}_{10}$ with $0-50 \mu \mathrm{g} \mathrm{m}^{-3}$ were, respectively, used in the analysis (Table 3).

The TNDPG b6 - (GST b6 - GST) model is found to be more reliable compared to the other models (Table 3 ).
Correlation analyses were also performed to determine the relationship between the trend of different models results (Table 3) and $\mathrm{PM}_{10}$ concentrations (Figs. 2, 3, 4, 5, 6). The purpose was to determine the correlation between variables on different location. The $\mathrm{PM}_{10}$ concentrations in Iran during the acquisition date in Sanandaj were higher than $50 \mu \mathrm{g} \mathrm{m}^{-3}$ and they were lower than 50 and $100\left(\mu \mathrm{g} \mathrm{m}^{-3}\right)$ in Klang Valley and Tehran, respectively. Therefore, the results of Table 3 for Iran in $0-50 \mu \mathrm{g} \mathrm{m}^{-3}$ and more than $100 \mu \mathrm{g} \mathrm{m}^{-3}$ of $\mathrm{PM}_{10}$ show the correlation analysis for 
Fig. 6 NLCC between different empirical models of temperature retrieval from Landsat ETM+ and $\mathrm{PM}_{10}$ concentrations in $0-50\left(\mu \mathrm{g} \mathrm{m}^{-3}\right)$ in Cheras, Malaysia
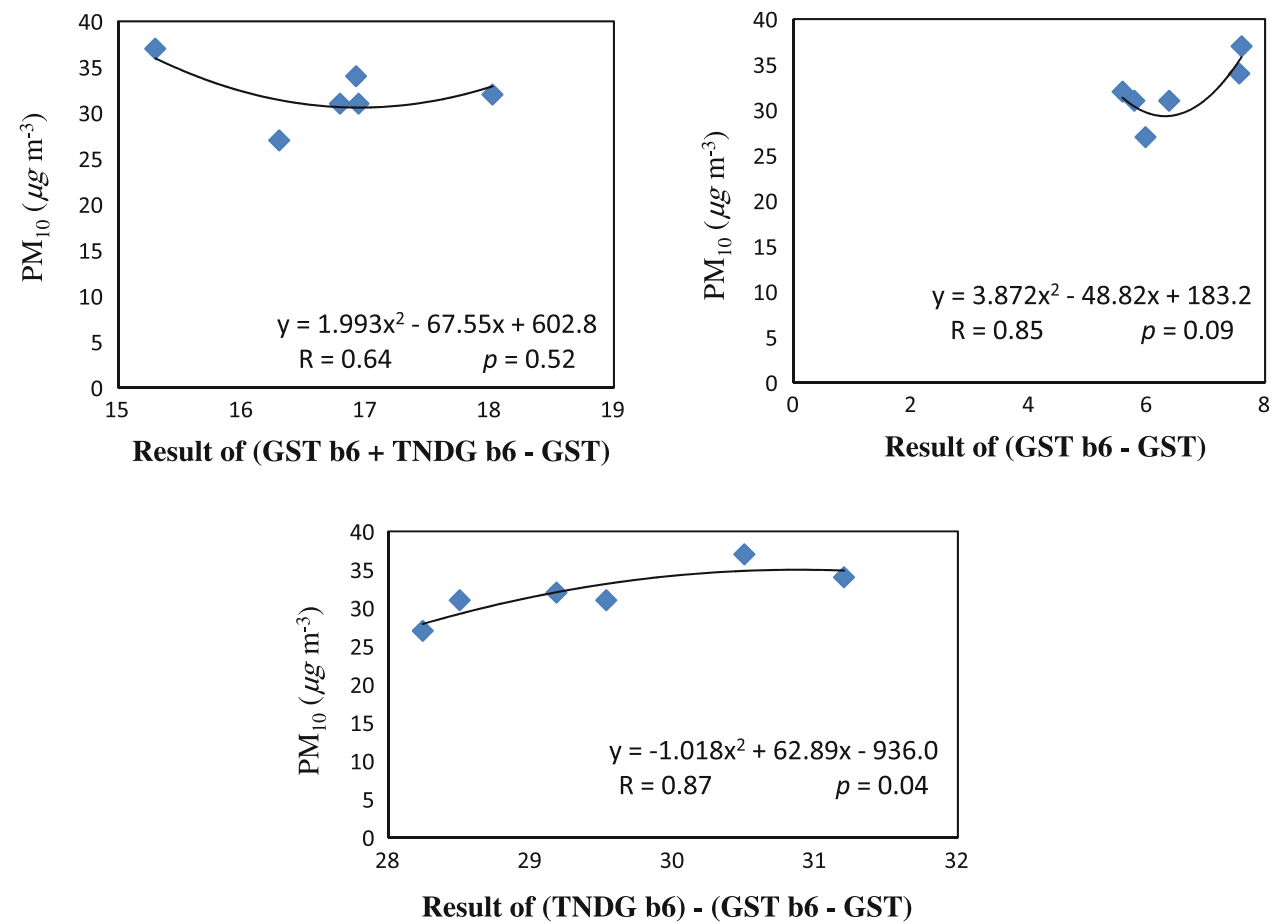

Tehran and Sanandaj, respectively. Then, correlation analyses were undertaken for $\mathrm{PM}_{10}$ concentrations in 50-100 $\mu \mathrm{g} \mathrm{m}^{-3}$ for both areas in Iran (Figs. 2, 3) and lower than $50 \mu \mathrm{g} \mathrm{m}^{-3}$ for three stations in Malaysia (Figs. 4, 5, 6).

The highest NLCC between different models of GST retrieval and $\mathrm{PM}_{10}$ concentrations in $50-100 \mu \mathrm{g} \mathrm{m}^{-3}$ in Tehran was acquired when the GST b6 - (NDPT b6 - GST) model was used in the analysis (Fig. 2). In Eq. (3), AEEGS and ES had no effect on the result. Moreover, the different value of AEEGS and ES in the Tehran stations (three stations) decreased the result of Eq. (1) compared to the result of this equation in Sanandaj (one station). This finding was confirmed by the result of Table 3 for Malaysia. As Table 3 shows, the overall result for the data of the three stations in Eq. (1) was obtained low in Malaysia.

The highest NLCC values in three stations in Malaysia were obtained the same for situations in Figs. 2 and 3 when GST b6 - (NDPT b6 - GST) was used in the analysis (Figs. 4, 5, 6). This result emphasizes that the GST b6 (NDPT b6 - GST) equation is more reliable than the other two equations to predict $\mathrm{PM}_{10}$ concentration. Equation (3) can be useful to eliminate the sensor problem of Landsat $\mathrm{ETM}+$. In Landsat ETM+, several lines of each swath are systematically replaced by simulated values (Hadjimitsis and Clayton 2009), which do not allow the researcher to classify the images. However, by determining the some GT point (depending on the study area size and assessment accuracy of study) and using the suggested method in this study, researchers will be able to remove the Landsat
ETM + problem. Converting the result of $\mathrm{PM}_{10}$ concentration for each point with their coordinate system in the Geographical Information System (GIS) allow the researcher to map the distribution of $\mathrm{PM}_{10}$ concentration in the atmosphere, as Sohrabinia and Khorshiddoust (2007) with the help of GIS were able to map the distribution of different ground pollution data.

\section{Conclusion}

Distribution and amount of PM concentration in atmosphere have become the subjects of heated debate because of their effect on environment and human health. In this study, due to the limitations of MODIS products concerning PM, the thermal infrared band of Landsat ETM+ was utilized to determine the $\mathrm{PM}_{10}$ concentration. Sanandaj for its dust storms from Iraq and Tehran for its high population and industrial points were selected as the study areas in Iran. Three models of GST retrieval from images consisting of GST b6 + TNDPG b6 - GST, GST b6 - GST, and TNDPG b6 - (GST b6 - GST) were used in the analysis. $\mathrm{PM}_{10}$ concentrations were divided into three sections including $0-50,50-100$, and $100 \mu \mathrm{g} \mathrm{m}^{-3}<\mathrm{PM}$. In order to prove the result of empirical equations for other areas, three stations in the Klang Valley, Malaysia were chosen. Results showed that the highest NLCC were acquired when the trend of the result of TNDPG b6 (GST b6 - GST) and the trend of $\mathrm{PM}_{10}$ concentration in 50-100 and 0-50 $\mathrm{g} \mathrm{m} \mathrm{m}^{-3}$ were used in the analysis for Iran 
and Malaysia, respectively. The findings of this study led the researchers to conclude that thermal band of Landsat ETM+ is useful and more reliable in determining its $\mathrm{PM}_{10}$ concentration and investigating its distribution. Using this method and the GIS environment, researchers will be able to overcome the Landsat ETM+ problem in thermal band about some swath with no DN.

Acknowledgments The researchers are grateful to Prof. Costas Varotsos from University of Athens for his comments about mechanism of emission and reflectance in remote sensing also we appreciate Mrs. Kazhal Habibzadeh from Sanandaj Environment Protection Organization for the hourly $\mathrm{PM}_{10}$ data.

\section{References}

Adamson I, Prieditis H, Vincent R (1999) Pulmonary toxicity of an atmospheric particulate sample is due to the soluble fraction. Toxicol Appl Pharmacol 157(1):43-50

Agarwal M, Tandon A (2010) Modeling of the urban heat island in the form of mesoscale wind and of its effect on air pollution dispersal. Appl Math Model 34(9):2520-2530

Al-saadi J, Szykman J, Pierce RB, Kittaka C, Neil D, Chu DA, Remer L, Gumley L, Prins E, Weinstock L, Macdonald C, Wayland R, Dimmick F, Fishman J (2005) Improving national air quality forecasts with satellite aerosol observations. Bulletin of the American Meteorological Society, 18 March 2005. American Meteorology Society. Doi:10.1175/BAMS-86-9-1249

Amanollahi J, Abdullah AM, Ramli MF, Pirasteh S (2010a) Urban heat island monitoring using Landsat satellite images processing, Tehran, Iran. In: third international conference on geoinformation technology for natural disaster management and rehabilitation. 19-20 October 2010, Chaiang Mai, Thailand

Amanollahi J, Kaboodvandpour SH, Abdullah AM (2010b) Evaluation of the effect of heat and vegetation cover changes of Syria desert in influences of on the recent dust storms in Iran using Landsat satellite processing. In: 3rd international conference on geoinformation technology for natural disaster management and rehabilitation. 19-20 October 2010, Chaiang Mai, Thailand

Amanollahi J, Abdullah AM, Farzanmanesh R, Ramli MF, Pirasteh S (2011a) $\mathrm{PM}_{10}$ distribution using remotely sensed data and GIS techniques; Klang Valley, Malaysia. Environ Asia 4(1):47-52

Amanollahi J, Kaboodvandpour S, Abdullah AM, Ramli MF (2011b) Accuracy assessment of moderate resolution image spectroradiometer products before and during dust storms. Int J Environ Sci Technol 8(2):373-380

Barsi JA, Hook SJ, Schott JR, Raqueno NG, Markham BL (2007) Landsat-5 thematic mapper thermal band calibration update. IEEE Geosci Remote Sens Soc Lett 4(4):552-555

Chrysoulakis N, Spiliotopoulos M, Domenikiotis C, Dalezios N (2003). Towards monitoring of regional atmospheric instability through MODIS/Aqua images. In: Proceedings of the International Symposium held at Volos, November

Coll C, Galve JM, Sánchez JM, Caselles V (2010) Validation of Landsat-7/ETM+ Thermal band calibration and atmospheric correction with ground based measurements. IEEE Trans Geosci Remote Sens 48(1):547-555

EQR (2006) Malaysia Environmental Quality Report 2006. Available online at: http://www.doe.gov.my/en/content/environmentalquality-report-eqr-2006

Gupta P, Christopher SA, Box MA, Box GP (2007) Multiyear satellite remote sensing of particulate matter air quality over Sydney, Australia. Int J Remote Sens 28(20):4483-4498
Hadjimitsis DG, Clayton CRI (2008) The use of an improved atmospheric correction algorithm for removing atmospheric effects from remotely sensed images using an atmospheresurface simulation and meteorological data. Meteorol Appl 15(3):381-387

Hadjimitsis DG, Clayton CLR (2009) Determination of aerosol optical thickness through the derivation of an atmospheric correction for short-wavelength Landsat TM and ASTER image data: an application to areas located in the vicinity of airports at UK and Cyprus. Appl Geomat 1(1-2):31-40

Hadjimitsis DG, Retalis A, Clayton CRI (2002) The assessment of atmospheric pollution using satellite remote sensing technology in large cities in the vicinity of airports. Water Air Soil Pollut Focus 2(5-6):631-640

Hadjimitsis DG, Clayton CRI, Hope VS (2004) An assessment of the effectiveness of atmospheric correction algorithms through the remote sensing of some reservoirs. Int $\mathrm{J}$ Remote Sens 25(18):3651-3674

Haywood J, Boucher O (2000) Estimates of the direct and indirect radiative forcing due to tropospheric aerosols: a review. Rev Geophys 38(4):513-543

IDOE (2009) Iran Department of environmental. Available online at http://kordestan.epo.ir/

IMO (2010) Iran meteorological organization. Available online at http://www.weather.ir/farsi/

Jonsson P, Bennet C, Eliasson I, Selin LE (2004) Suspended particulate matter and its relations to the urban climate in Dar es Salaam, Tanzania. Atmos Environ 38(25):4175-4181

Kampe TU (2008) Data analysis from remote sensing to better constrain emission and transport of carbonaceous aerosol and carbon monoxide resulting from burning processes. $\mathrm{PhD}$ thesis, Colorado University, p 272

Kaufman YJ (1989) The atmospheric effect on remote sensing and its correction. In: Asrar G (ed) Theory and application of optical remote sensing. Wiley, New York, pp 336-428

Kaufman YJ, Wald AE, Remer LA, Gao BC, Li RR, Luke F (1997) The MODIS 2.1- $\mathrm{m}$ channel-correlation with visible reflectance for use in remote sensing of aerosol. IEEE Trans Geosci Remote Sens 35(5):1268-1298

Kaufman YJ, Tanre D, Boucher O (2002) A satellite view of aerosols in climate systems. Nature 419:215-223

King MD, Kaufman YJ, Menzel P, Tanr ED (1992) Determination of cloud, aerosol and water vapor properties from the moderate resolution imaging spectrometer (MODIS). IEEE Trans Geosci Remote Sens 30(1):2-27

Krewski D, Bumett RT, Goldberg MS, Hoover K, Siemiatycki J, Jerrett M, Abrahamowicz A, White WH (2000) Reanalysis of the Harvard six cities study and the American Cancer Society study of particulate air pollution and mortality: a special report of the Institute's Particle Epidemiology Reanalysis Project. Health Effects Institute, Cambridge. Available online at: http://pubs.healtheffects.org/getfile.php

Landsat 7 Science Data User Handbook (2010) Available online at: http://Landsathandbook.gsfc.nasa.gov/handbook.html (Last accessed 15 May 2010)

Li JJ, Wang XR, Wang XJ, Ma WC, Zhang H (2009) Remote sensing evaluation of urban heat island and its spatial pattern of the Shanghai metropolitan area, China. Ecol Complex 6(4):413-420

Ling-Jun L, Ying W, Qiang Z, Tong Y, Yue Z, Jun J (2007) Spatial distribution of aerosol pollution based on MODIS data over Beijing, China. J Environ Sci 19(8):955-960

Martonchik JV, Diner DJ (1992) Retrieval of aerosol and land surface optical properties from multi-angle satellite imagery. IEEE Trans Geosci Remote Sens 30(2):223-230

Mazzoni D, Logan J, Diner D, Kahn R, Tong L, Li Q (2007) A data-mining approach to associating MISR smoke plume heights with MODIS fire measurements. Remote Sens Environ 107(1-2):138-148 
MDOE (2010) Malaysian Department of Environment. Available online at: http://www.doe.gov.my/portal/

MHME (2010) Ministry of health and Medical Education. Available online at: http://behdasht.gov.ir//uploads/1_97_behdasht\%2087 1004.pdf

MMD (2009) Malaysian Meteorological Department. Available online at: http://www.met.gov.my/index.php?

Odabasi M, Bagiroz HO (2002) Sulfate dry deposition fluxes and overall deposition velocities measured with a surrogate surface. Sci Total Environ 297(1-3):193-201

Quan J, Zhang X, Zhang Q, Guo J, Vogt RD (2008) Importance of sulfate emission to sulfur deposition at urban and rural sites in China. Atmos Res 89(3):283-288

Retalis A (1998) Study of atmospheric pollution in large cities with the use of satellite observations: development of an atmospheric correction algorithm applied to polluted urban areas. $\mathrm{PhD}$ thesis, Athens University, Athens

Retalis A, Cartalis C, Athanassiou E (1999) Assessment of the distribution of aerosols in the area of Athens with the use of Landsat Thematic Mapper. Int J Remote Sens 20(5):939-945

Schott JR, Barsi JA, Nordgren BL, Raqueno NG, Alwis DD (2001) Calibration of Landsat thermal data and application to water resource studies. Remote Sens Environ 78:108-117

Seinfeld JH, Pandis SN (1998) Atmospheric chemistry and physicsfrom air pollution to climate change. Wiley, London, pp 10541088

Sohrabinia M, Khorshiddoust AM (2007) Application of satellite data and GIS in studying air pollution in Tehran. Habit Int 31(2): 268-275
TM (2010) Tehran municipality. Available online at: http://olden. tehran.ir/

Wald L, Basly L, Balleynaud JM (1999) Satellite data for the air pollution mapping. In: Nieeuwenhuis GJA, Vaugham RA, Molenaar M (eds) Proceedings of the 18th EARseL symposium on operational sensing for sustainable development, Enschede, 11-14 May 1998), pp 133-139

Wang J, Christopher SA (2003) Inter comparison between satellitederived aerosol optical thickness and $\mathrm{PM}_{2.5}$ mass: implication for air quality studies. Geophys Res Lett 30(21):2095-2099

Wang T, Li S, Jiang F, Gao L (2006) Investigations of main factors affecting tropospheric nitrate aerosol using a coupling model. China Particuol 4(6):336-341

WHO (2005) Air Quality Guidelines global update 2005. Report on a Working Group meeting, 18-20 October, Bonn. Available online at: http://www.euro.who.int/document/e87950

Williams R, Suggs J, Rea A, Leovic K, Vette A, Croghan C, Sheldon L, Rodes Ch, Thomburg J, Ejire A, Herbst M, Sanders W (2003) The research triangle park particulate matter panel study: PM mass concentration relationships. Atmos Environ 37(38):53495363

Xu HQ, Chen BQ (2004) Remote sensing of the urban heat island and its changes in Xiamen City of SE China. J Environ Sci 16(2):276-281

Yun HJ, Yi SM, Kim YP (2002) Dry deposition fluxes of ambient particulate heavy metals in a small city, Korea. Atmos Environ 36(35):5449-5458 